\title{
$\mathrm{KNbO}_{3}$ 치환이 $(\mathrm{Li}, \mathrm{Na}, \mathrm{K})(\mathrm{Nb}, \mathrm{Sb}, \mathrm{Ta}) \mathrm{O}_{3}$ 계 세라믹스의 유전 및 압전 특성에 미치는 영향
}

\author{
노정래 ${ }^{1}$, 류주현 ${ }^{1, a}$, 이상돈 $^{2}$ \\ 1 세명대학교 전기공학과 \\ 2 강릉원주대학교 전기공학과
}

\section{Effects of $\mathrm{KNbO}_{3}-$ Substitution on the Dielectric and Piezoelectric Properties of $(\mathrm{Li}, \mathrm{Na}, \mathrm{K})(\mathrm{Nb}, \mathrm{Sb}, \mathrm{Ta}) \mathrm{O}_{3}$ System Ceramics}

\author{
Jungrae $\mathrm{Noh}^{1}, \mathrm{Ju}-\mathrm{Hy}$ un Yoo ${ }^{1, \mathrm{a}}$, and Sang-Don Lee ${ }^{2}$ \\ ${ }^{1}$ Department of Electrical Engineering, Semyung University, Jecheon 390-701, Korea \\ ${ }^{2}$ Department of Electrical Engineering, Gangneung-Wonju National University, Wonju 220-711, Korea
}

(Received January 28, 2013; Revised February 5, 2013; Accepted February 12, 2013)

\begin{abstract}
In this study, $\mathrm{KNbO}_{3}$-substituted $(\mathrm{Li}, \mathrm{Na}, \mathrm{K})(\mathrm{Nb}, \mathrm{Sb}, \mathrm{Ta}) \mathrm{O}_{3}$ ceramics were investigated to develop $\mathrm{Pb}$-free composition ceramics for multilayer actuator and energy harvester applications. The $\mathrm{X}$-ray diffraction analysis indicated that all samples were pure perovskite phase and no secondary phase was found. A tetragonality as a function of $\mathrm{KNbO}_{3}$ substitution showed the maximum value at $1.5 \mathrm{~mol} \% \mathrm{KNbO}_{3}$ and then decreased. The SEM image analysis showed the maximum grain size of $3.14 \mu \mathrm{m}$ at $1.5 \mathrm{~mol} \% \mathrm{KNbO}_{3}$. In the composition ceramics with $1.5 \mathrm{~mol} \% \mathrm{KNbO}_{3}$ sintered at $1,100^{\circ} \mathrm{C}$, excellent properties of density $=4.75 \mathrm{~g} / \mathrm{cm}^{3}$, electromechanical coupling factor $\left(\mathrm{k}_{\mathrm{p}}\right)=0.50$ and piezoelectric constant $\left(\mathrm{d}_{33}\right)=290 \mathrm{pC} / \mathrm{N}$ were obtained, respectively, suitable for piezoelectric actuator and energy harvester applications.
\end{abstract}

Keywords: NKN, $\mathrm{Pb}$-free, $\mathrm{KNbO}_{3}$, Multilayer actuator, Energy harvester

\section{1. 서 론}

압전 액츄에이터 및 에너지하베스터에 응용되는 압 전 세라믹스는 $\mathrm{Pb}(\mathrm{Zr}, \mathrm{Ti}) \mathrm{O}_{3}$ 계 세라믹스가 주류를 이 루었으나, $\mathrm{PbO}$ 가 포함되어 있는 물질은 $1,000^{\circ} \mathrm{C}$ 부근 에서 급격한 휘발에 따른 손실과 그에 따른 조성의

\footnotetext{
a. Corresponding author; juhyun57@semyung.ac.kr
}

Copyright (C2013 KIEEME. All rights reserved.

This is an Open-Access article distributed under the terms of the Creative Common Attribution Non-Commercial License (http://creativecommons.org/licenses/by-nc/3.0) which permits unrestricted non-commercial use, distribution, and reproduction in any medium, provided the original work is properly cited.
변화로 인하여 압전 특성의 감소와 인체에 치명적인 중독 문제를 야기시키며, 환경오염에 관한 문제로 인 하여 WEEE (waste electrical and electronic equipment), RoHS (restriction of hazardous substance) 등에 따른 환경규제 정책에 따라 $\mathrm{Pb}$ 를 함 유한 전기 전자제품의 생산이 제한받고 있는 실정이 다 [1]. 따라서, 이 PZT계 조성세라믹스를 대체할 무연 압전 세라믹스 개발이 필요하다

현재, Lead-free 세라믹스 중 압전 특성이 우수한 $\left(\mathrm{Na}_{0.5} \mathrm{~K}_{0.5}\right) \mathrm{NbO}_{3}(\mathrm{NKN})$ 을 기반으로 한 조성 세라믹스 에 대해 많은 연구가 이루어지고 있다.

$\mathrm{NKN}$ 계 조성을 일반적인 소결 방법에 의해 소결 
하였을 경우 $\mathrm{PZT}$ 계 조성에 비하여 낮은 유전 및 압전 특성 ( $d_{33}=80[\mathrm{pC} / \mathrm{N}], k_{p}=36 \sim 40 \%, Q_{m}=130$ )을 보이 고 있다. 이러한 이유는 조성에 포함되는 $\mathrm{K}_{2} \mathrm{CO}_{3}$ (89 $\left.1^{\circ} \mathrm{C}\right)$ 와 $\mathrm{Na}_{2} \mathrm{CO}_{3}\left(851^{\circ} \mathrm{C}\right)$ 의 낮은 휘발온도가 원인으로 작용하여 충분히 치밀화된 세라믹스를 얻기 어렵기 때 문이다. 이러한 단점을 극복하기 위하여 여러 가지 방 법들이 소개되어지고 있다 [2,3]. 그 중에서, SPS (spark plasma sintering), hot pressing, hot forging, and RTGG (reactive template grain growth)와 같은 특별한 소결 공정은 높은 성능의 세라믹스를 제조하기 위하여 활용되어져 왔다 [4-7].

그러나 이러한 특별한 소결 공정은 제조비가 매우 비싸다. 그러므로 고성능 세라믹스의 제조를 위한 새로 운 방법은 $\mathrm{Bi}, \mathrm{Li}, \mathrm{Ta}, \mathrm{Sb}, \mathrm{BiFeO}_{3}, \mathrm{KNbO}_{3}$ [8-10] 등의 치환과 $\mathrm{CuO}, \mathrm{ZnO}$ 등과 같은 산화물 소결 조제의 첨가 를 통하여 $\mathrm{NKN}$ 세라믹스의 밀도를 향상시킬 수 있고 또한 $\mathrm{KNbO}_{3}$ 자체는 용융점이 $1,054^{\circ} \mathrm{C}$ 로 낮기 때문에 $\mathrm{NKN}$ 조성에 용융점이 낮은 화합물을 치환시키는 법을 통해 유전 및 압전 특성 또한 확실히 향상시킬 수 있 다는 것이 입증되어져 왔다.

본 연구에서는 $(1-x)\left(\mathrm{Li}_{0.04}\left(\mathrm{Na}_{0.515} \mathrm{~K}_{0.46}\right)_{0.96}\left(\mathrm{Nb} 0.81 \quad \mathrm{~T}_{0.15} \mathrm{Sb}_{0.04}\right) \mathrm{O}_{3}\right.$ $+0.1 \mathrm{wt} \% \mathrm{CoO}+x \mathrm{KNbO}_{3}$ 의 조성에 대하여 $\mathrm{KNbO}_{3}$ 변화에 따른 유전 및 압전 특성을 조사하였다.

\section{2. 실험 방법}

본 실험에서는 우수한 압전 특성을 가지는 무연 압전 액츄에이터용 압전 세라믹스를 개발하기 위하여 $(\mathrm{Li}, \mathrm{Na}, \mathrm{K})(\mathrm{Nb}, \mathrm{Ta}, \mathrm{Sb}) \mathrm{O}_{3}$ 조성 세라믹스에 $\mathrm{KNbO}_{3}$ 치환 량에 따른 유전 및 압전 특성을 관찰하였다.

$$
\begin{aligned}
& (1-x) \mathrm{Li}_{0.04}\left(\mathrm{Na}_{0.545} \mathrm{~K}_{0.46}\right)_{0.98}\left(\mathrm{Nb}_{0.81} \mathrm{Ta}_{0.15} \mathrm{Sb}_{0.04}\right) \mathrm{O}_{3} \\
& +0.1 \mathrm{wt} \% \mathrm{CoO}+x \mathrm{KNbO}_{3}(x=0,1.5,3,4.5,6 \mathrm{~mol} \%)
\end{aligned}
$$

99\% 이상의 순도를 가지는 시료를 조성에 따라 $10^{-4}$ $\mathrm{g}$ 까지 측량하였고 아세톤을 분산매로 하여 $3 \Phi$ zirconia ball을 사용하여 24시간 동안 혼합, 분쇄하였 다. 혼합 분쇄된 시료는 $900^{\circ} \mathrm{C}, 6$ 시간 동안 하소하였다. 하소된 시료들은 첨가제로 $0.1 \mathrm{wt} \% \mathrm{CoO}$ 와 $\mathrm{KNbO}_{3}$ $(\mathrm{x}=0,1.5,3,4.5,6)$ 를 $\mathrm{mol} \%$ 에 맞게 측량한 후 2 차 혼 합 분쇄하였다. 건조된 시료에 PVA (0.5 wt\% 수용액) $5 \mathrm{wt} \%$ 를 첨가하고 $17 \Phi$ 성형틀에 $2 \mathrm{ton} / \mathrm{cm}^{2}$ 의 힘을 가 하여 성형하였다. 성형된 시편은 $600^{\circ} \mathrm{C}$ 에서 3 시간 동안
PVA를 태워버린 후, 승하강 온도 구배를 $5^{\circ} \mathrm{C} / \mathrm{min}$ 로 하여 $1,100^{\circ} \mathrm{C}$ 에서 5 시간 소결하였다. 소결된 시편을 1 $m m$ 의 두께로 연마하고 $\mathrm{Ag}$ 전극을 스크린 프린트법으 로 도포한 뒤 $600^{\circ} \mathrm{C}$ 에서 10 분간 열처리하였고, $120^{\circ} \mathrm{C}$ 실리콘 오일 속에서 $3 \mathrm{kV} / \mathrm{mm}$ 의 직류 전계를 10 분간 인가한 후 온도를 상온까지 내리면서 30 여분에 걸쳐 분극하였다. 분극된 시편을 24 시간 경과 후 impedence analyzer (Agilent 4294)를 이용하여 주파수 및 impedence 특성을 측정하였고, LCR meter (ANDO AG 4304)를 이 용하여 $1 \mathrm{KHz}$ 의 주파수로 유전 특성을 측정하였다. 시편 의 압전 및 유전 특성은 $\mathrm{IEEE}$ 에서 규정에 따라 공진 반 공진 법을 이용하여 계산하였으며, 시편의 미세 구조 및 결정 구조는 각각 $\mathrm{SEM}$ (scanning electron microscope)과 $\mathrm{XRD}$ (X-ray diffraction)를 이용하여 관찰하였다.

\section{3. 결과 및 고찰}

그림 1 은 $\mathrm{KNbO}_{3}$ 치환량에 따른 시편의 $\mathrm{XRD}$ 회절 분석을 나타낸 그림이다. XRD 회절 분석 결과 그림 1(a) 에서 보이듯이 모든 샘플에서 단일 페로브 스카이트 구 조를 보이며 tetragonal (정방정계) 대칭 구조를 나타내고 있다. 이차 상은 발견되지 않았다. $\mathrm{KNbO}_{3}$ 치환은 조성에 대하여 등가 치환이므로 상의 변화 또한 발견되지 않았 다. 그림 $1(\mathrm{~b})$ 는 $43^{\circ}$ 에서 $48^{\circ}$ 까지의 확대된 그림이다.
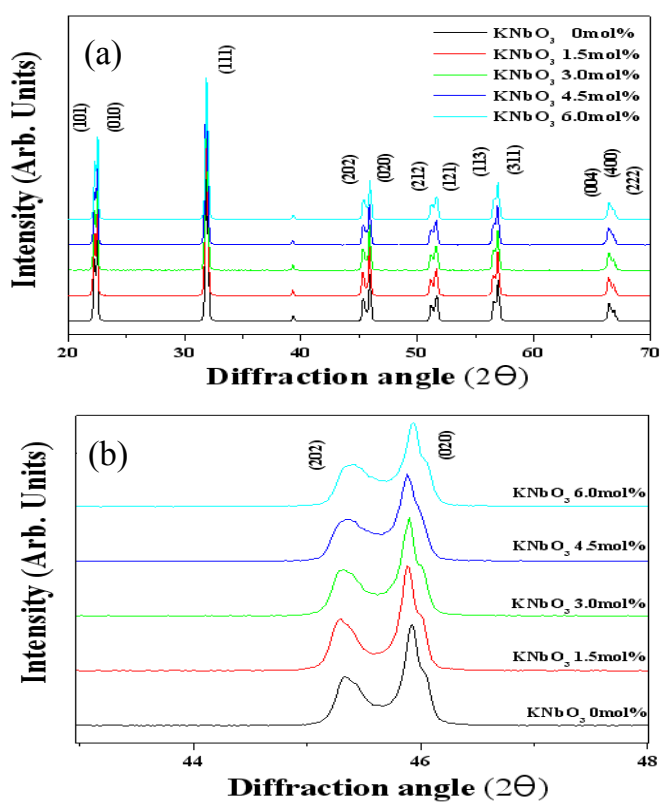

Fig. 1. The $\mathrm{X}$-ray diffraction pattern of specimens as a function of the amount of $\mathrm{KNbO}_{3}$ substitution. 

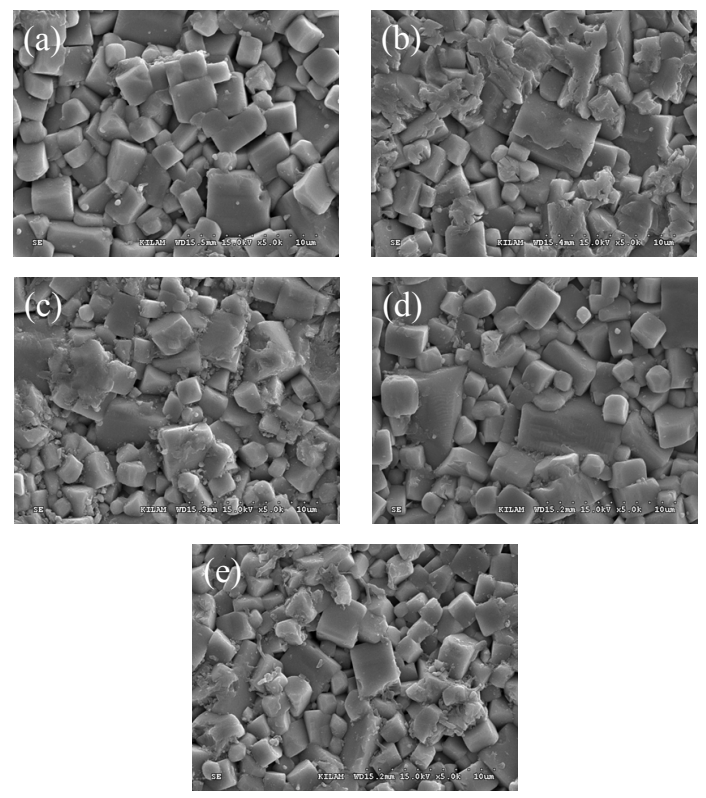

Fig. 2. The scanning electron microscopy (SEM) of pecimens as a function of the amount of $\mathrm{KNbO}_{3}$ substitution $\left(0,1.5,3,4.5,6 \mathrm{~mol} \% \mathrm{KNbO}_{3}\right)$.

$\mathrm{KNbO}_{3}$ 치환량에 증가에 따라 tetragonality는 증가 하여 $1.5 \mathrm{~mol}_{\%} \mathrm{KNbO}_{3}$ 에서 가장 높은 값 1.012 을 보 인 후 이후 감소하는 경향을 보였다. 그림 2 는 $\mathrm{KNbO}_{3}$ 치환량에 따른 시편의 미세구조를 주사전자 현미경 ( $\mathrm{SEM)으로} \mathrm{나타낸} \mathrm{사진이다.} \mathrm{KNbO}_{3}$ 치환량 이 증가함에 따라, grain size (입경)은 점차 증가하여 $1.5 \mathrm{~mol} \% \mathrm{KNbO}_{3}$ 에서 가장 높은 값 $3.14 \mu \mathrm{m}$ 을 보인 후 서서히 감소한다. Grain size (입경)의 증가 원인 으로 $\mathrm{KNbO}_{3}$ 는 기본 조성식에 하소 후 치환된 것으 로서 $\mathrm{KNbO}_{3}$ 에서 $\mathrm{K}^{+}$이온은 소결 중 휘발하는 $\mathrm{A}$-site 의 $\mathrm{K}^{+}$이온 자리에 등가 치환되어 $\mathrm{K}^{+}$이온을 보충하 여 소결성을 개선하였고, 더불어 $1,054^{\circ} \mathrm{C}$ 의 낮은 녹는 점을 가지는 $\mathrm{KNbO}_{3}$ 가 소결과정 중 액상을 형성하여 액상 소결하여 이 또한 소결 성을 개선시켜 주었기 때문으로 사료된다. 이 후 감소하는 이유로는 액상의 과다한 형성이 grain의 성장을 억제하였기 때문으로 보인다.

그림 3 은 $\mathrm{KNbO}_{3}$ 치환량에 따른 시편의 밀도 특 성을 보여준다. $\mathrm{KNbO}_{3}$ 치환량의 증가에 따라, 밀도는 서서히 증가하여 $3 \mathrm{~mol} \% \mathrm{KNbO}_{3}$ 에서 최대의 값 $4.766 \mathrm{~g} / \mathrm{cm}^{3}$ 을 나타낸 후 감소한다. 증가하는 이유로 $\mathrm{KNbO}_{3}$ 치환에 따른 액상의 형성, 액상은 소결의 초

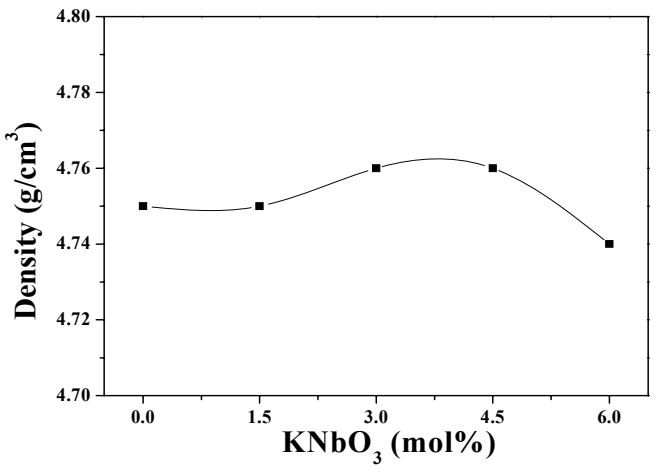

Fig. 3. Density of specimens as a function of the amount of $\mathrm{KNbO}_{3}$ substitution.

기 단계에 입자 배열을 향상시켜 grain 성장에 영향 을 미친 것으로 보이며, 감소하는 이유로는 과다하게 생성된 액상이 grain의 성장을 억제하였기 때문으로 사료 된다. $\mathrm{KNbO}_{3}$ 치환량이 증가함에 따라, 전기기계 결합계수 $\left(\mathrm{k}_{\mathrm{p}}\right)$, 압전 상수 $\left(\mathrm{d}_{33}\right)$ 의 물성 값들은 유사한 경향을 보였다. 전기기계결합계수 $\left(\mathrm{k}_{\mathrm{p}}\right)$ 와 압전상수 $\left(\mathrm{d}_{33}\right)$ 는 $\mathrm{KNbO}_{3}$ 치환량이 증가함에 따라 $1.5 \mathrm{~mol} \% \mathrm{KNbO}_{3}$ 까지 증가 후 감소한다.

그림 4 는 $\mathrm{KNbO}_{3}$ 치환량에 따른 시편의 유전 및 압전 특성을 보여준다. 이러한 결과는 $\mathrm{KNbO}_{3}$ 치환량 이 $1.5 \mathrm{~mol} \%$ 이하일 때에는 입계에 액상을 형성하여 기공의 감소와 소결성의 개선에 기인한 것이라 보이 며, 또 다른 이유로 결정 구조의 특성에서 확인하였 듯이 $1.5 \mathrm{~mol} \% \mathrm{KNbO}_{3}$ 에서 가장 높은 tetragonality 를 나타내고 있기 때문으로 사료된다. 이 후 급격히 감소하는 이유는 $\mathrm{KNbO}_{3}$ 과잉 치환에 따른 원인으로 사료된다. 전기기계결합계수 $\left(\mathrm{k}_{\mathrm{p}}\right)$ 와 압전상수 $\left(\mathrm{d}_{33}\right)$ 는 $\mathrm{KNbO}_{3}$ 치환량이 $1.5 \mathrm{~mol} \%$ 일 때 0.5 와 $290 \mathrm{pC} / \mathrm{N}$ 의 최적의 값을 각각 보였다.

반면에, 기계적 품질계수 $\left(\mathrm{Q}_{\mathrm{m}}\right)$ 는 전기기계 결합계수 $\left(\mathrm{k}_{\mathrm{p}}\right)$ 와 압전 상수 $\left(\mathrm{d}_{33}\right)$ 의 반대되는 경향을 보이고 있다. $6 \mathrm{~mol} \% \mathrm{KNbO}_{3}$ 치환량을 갖는 시편에서 기계적 품질 계수 $\left(\mathrm{Q}_{\mathrm{m}}\right)$ 은 66 의 최댓값을 나타내었으며 유전상수는 $\mathrm{KNbO}_{3}$ 치환량의 증가에 따라 계속적으로 감소하는 경향을 나타내었다. 이러한 결과는 그림 2 미세구조 특성과 그림 3 밀도 특성에서 확인하였듯이 grain size (입경)의 감소에 따른 변화로 사료된다. Grain $\operatorname{size}$ (입경)의 감소에 따라 세라믹은 더 치밀하고 단 단해지며 기계적품질계수 $\left(\mathrm{Q}_{\mathrm{m}}\right)$ 의 증가 원인이 된다. 

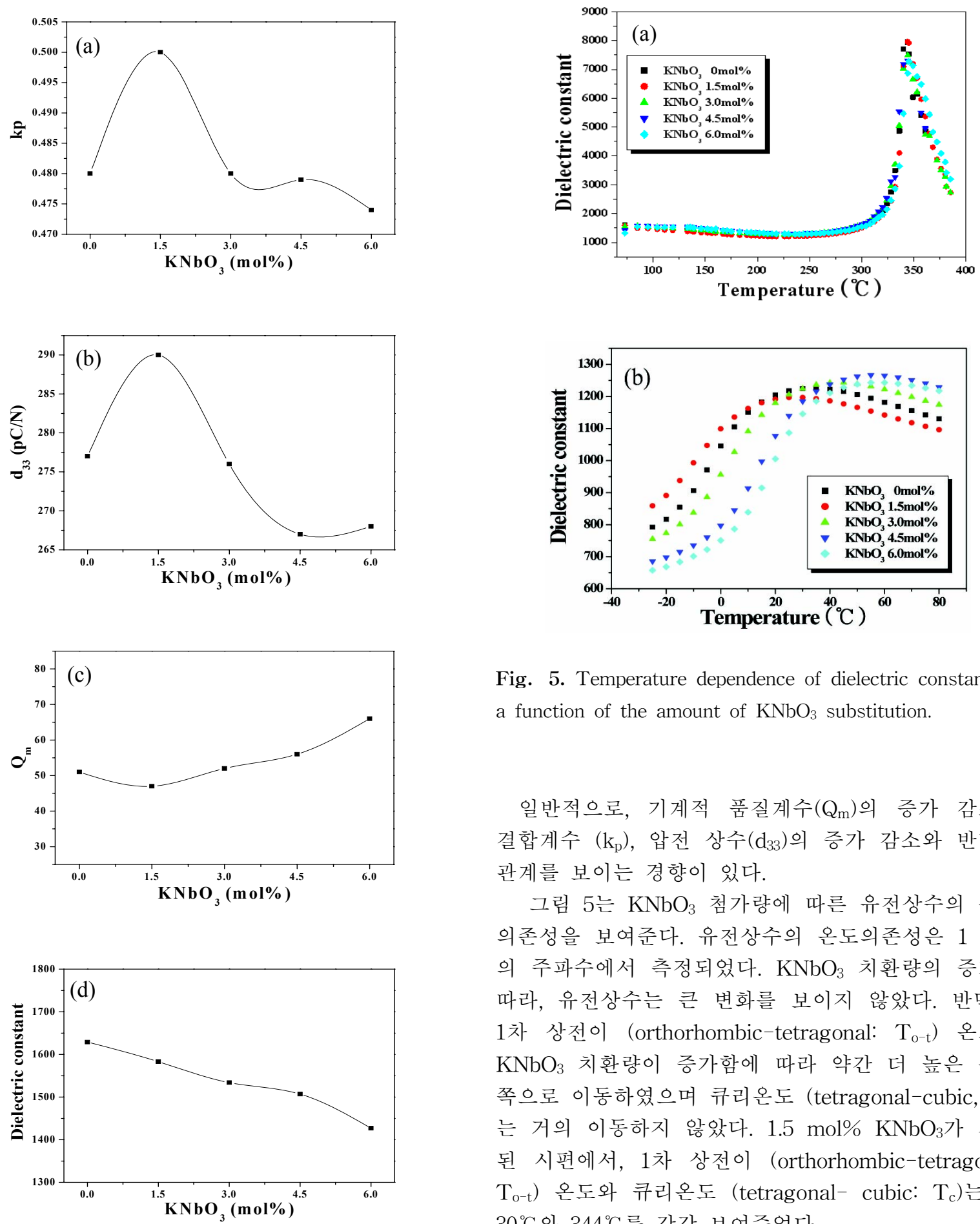

Fig. 4. Dielectric and piezoelectric properties of the ceramics as a function of the amount of $\mathrm{KNbO}_{3}$ substitution [(a) electromechanical coupling factor $\mathrm{kp}$, (b) piezoelectric constant $\mathrm{d}_{33}$, (c) mechanical quality factor Qm, and (d) dielectric constant $\mathrm{er}]$.

Fig. 5. Temperature dependence of dielectric constant as a function of the amount of $\mathrm{KNbO}_{3}$ substitution.

일반적으로, 기계적 품질계수 $\left(\mathrm{Q}_{\mathrm{m}}\right)$ 의 증가 감소는 결합계수 $\left(\mathrm{k}_{\mathrm{p}}\right)$, 압전 상수 $\left(\mathrm{d}_{33}\right)$ 의 증가 감소와 반비례 관계를 보이는 경향이 있다.

그림 5 는 $\mathrm{KNbO}_{3}$ 첨가량에 따른 유전상수의 온도 의존성을 보여준다. 유전상수의 온도의존성은 $1 \mathrm{kHz}$ 의 주파수에서 측정되었다. $\mathrm{KNbO}_{3}$ 치환량의 증가에 따라, 유전상수는 큰 변화를 보이지 않았다. 반면에, 1 차 상전이 (orthorhombic-tetragonal: $\mathrm{T}_{0-\mathrm{t}}$ ) 온도는 $\mathrm{KNbO}_{3}$ 치환량이 증가함에 따라 약간 더 높은 온도 쪽으로 이동하였으며 큐리온도 (tetragonal-cubic, $\mathrm{T}_{\mathrm{c}}$ ) 는 거의 이동하지 않았다. $1.5 \mathrm{~mol} \% \mathrm{KNbO}_{3}$ 가 치환 된 시편에서, 1 차 상전이 (orthorhombic-tetragonal: $\mathrm{T}_{\mathrm{o}-\mathrm{t}}$ ) 온도와 큐리온도 (tetragonal- cubic: $\mathrm{T}_{\mathrm{c}}$ )는 약 $30^{\circ} \mathrm{C}$ 와 $344^{\circ} \mathrm{C}$ 를 각각 보여주었다.

그림 6 은 $\mathrm{KNbO}_{3}$ 첨가량에 따른 히스테리시스 곡 선을 보여준다. $\mathrm{KNbO}_{3}$ 첨가량의 증가에 따라 잔류 분극은 증가하여 $1.5 \mathrm{~mol} \% \mathrm{KNbO}_{3}$ 에서 최댓값 $6.3 \mu$ $\mathrm{C} / \mathrm{cm}^{2}$ 을 보인 후 감소하였으며, 항전 계는 $\mathrm{KNbO}_{3}$ 첨 가량의 증가에 따라 계속해서 감소하는 경향을 보였다. 


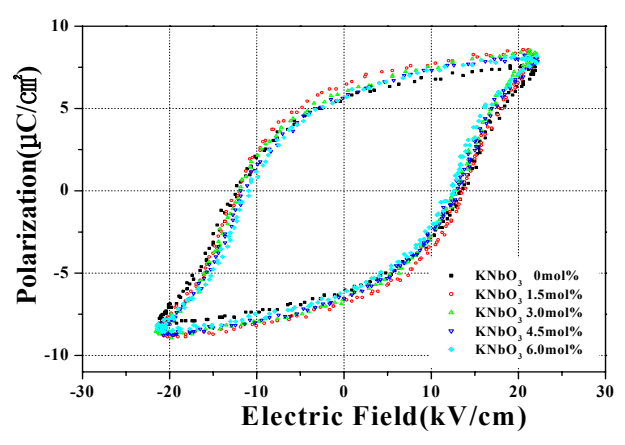

Fig. 6. P-E hysteresis loops as a function of the amount of $\mathrm{KNbO}_{3}$ substitution.

잔류 분극 $\left(P_{r}\right)$ 과 항전계 $\left(E_{c}\right)$ 는 $5.5 \mu \mathrm{C} / \mathrm{cm}^{2}, 6.3 \mu$ $\mathrm{C} / \mathrm{cm}^{2}, 6.08 \mu \mathrm{C} / \mathrm{cm}^{2}, 5.5 \mu \mathrm{C} / \mathrm{cm}^{2}, 5.7 \mu \mathrm{C} / \mathrm{cm}^{2}$ 과 13.95 $\mathrm{kV} / \mathrm{cm}, 13.5 \mathrm{kV} / \mathrm{cm}, 12.75 \mathrm{kV} / \mathrm{cm}, 12.6 \mathrm{kV} / \mathrm{cm}$, $12.45 \mathrm{kV} / \mathrm{cm}$ 로 각각 조사되었다.

\section{4. 결 론}

본 연구에서는 우수한 유전 및 압전 특성을 갖는 무연 압전 액츄에이터 및 에너지하베스터용 압전 세 라믹스를 개발하기 위하여 $(\mathrm{Li}, \mathrm{Na}, \mathrm{K})(\mathrm{Nb}, \mathrm{Ta}, \mathrm{Sb}) \mathrm{O}_{3}$ 조 성 세라믹스에 $\mathrm{KNbO}_{3}$ 를 치환시켜 치환량에 따른 유 전 및 압전 특성을 관찰하였으며 조사한 결과는 다음 과 같다.

1. $\mathrm{KNbO}_{3}$ 치환량에 증가에 따라 tetragonality는 증 가하여 $1.5 \mathrm{~mol}^{\circ} \mathrm{KNbO}_{3}$ 에서 가장 높은 값 1.012 을 보인 후 이후 감소하는 경향을 보였다.
2. 전기기계결합계수 $\left(\mathrm{k}_{\mathrm{p}}\right)$ 와 압전상수 $\left(\mathrm{d}_{33}\right)$ 는 $\mathrm{KNbO}_{3}$ 치 환량이 증가함에 따라 $1.5 \mathrm{~mol} \% \mathrm{KNbO}_{3}$ 에서 최 적의 값 $0.5,290 \mathrm{pC} / \mathrm{N}$ 의 값을 나타내었다. 이러 한 결과는 $\mathrm{KNbO}_{3}$ 치환량이 $1.5 \mathrm{~mol} \%$ 일 때 입계 에 액상을 형성하여 소결성의 개선에 기인한 것 으로 보인다.

3. 모든 시편들은 $1,100^{\circ} \mathrm{C}$ 의 온도에서 소결되었으며 $\mathrm{KNbO}_{3}$ 치환량이 $1.5 \mathrm{~mol} \%$ 일 때 밀도, 전기기계 결합계수, 기계적 품질계수, 유전상수 및 압전상 수는 각각 $4.75 \mathrm{~g} / \mathrm{cm}^{3}, 0.5,47,1,583,290 \mathrm{pC} / \mathrm{N}$ 으 로 최적의 특성 값을 보였다.

\section{REFERENCES}

[1] Y. Saito, H. Takao, T. Tani, T. Nonoyama, K. Takatori, T. Homma, T. Nagaya, and M. Nagamura, Nature, 432, 84 (2004).

[2] Y. Zhao, Y. Zhao, R. Huang, R. Liu, and H. Zhou, J. Am. Ceram. Soc., 94, 656 (2011).

[3] H. Mgbemere, R. Herber, and G. Schneider, J. Eur. Ceram. Soc., 29, 20091729.

[4] Y. Lee, D. Kim, J. Yoo, I. Kim, J. Song, and J. Hong, J. Kor. Phys. Soc., 22, 489 (2009).

[5] B. Seo and J. Yoo, J. Kor. Phys. Soc., 23, 617 (2010).

[6] Y. Lee, J. Yoo, K. Lee, I. Kim, J. Song, and Y. Park, J. Alloys Comp., 506, 872 (2010).

[7] D. Kim, J. Yoo, I. Kim, and J. Song, J. Appl. Phys., 105, 061642 (2009).

[8] E. Hollenstein, M. Davis, D. Damjanovic, and N. Setter, Appl. Phys. Lett., 87, 3182905 (2005).

[9] Y. Guo, K. Kakimoto, and H. Ohsato, Appl. Phys. Lett., 85, 4121 (2004).

[10] H. Wang, X. Zhang, and Y. Dai, Mater. Lett., 67, 145 (2012).

[11] J. Noh and J. Yoo, International Conference on Advenced Electromaterials, FM778 (2011). 